Review

\title{
Oxidative stress and frailty: A systematic review and synthesis of the best evidence
}

\author{
Pinar Soysal ${ }^{\mathrm{a}}$, Ahmet Turan Isik ${ }^{\mathrm{b}}$, Andre F. Carvalho ${ }^{\mathrm{c}}$, Brisa S. Fernandes ${ }^{\mathrm{d}, \mathrm{e}}$, \\ Marco Solmi ${ }^{\mathrm{f}, \mathrm{g}, \mathrm{h}}$, Patricia Schofield ${ }^{\mathrm{i}}$, Nicola Veronese ${ }^{\mathrm{h}, \mathrm{j}}$, Brendon Stubbs ${ }^{\mathrm{i}, \mathrm{k}, \mathrm{l}, \mathrm{m}, *}$ \\ a Kayseri Education and Research Hospital, Geriatric Center, Kayseri, Turkey \\ b Center for Aging Brain and Dementia, Department of Geriatric Medicine, Dokuz Eylul University, Faculty of Medicine, Izmir, Turkey \\ ${ }^{c}$ Department of Clinical Medicine and Translational Psychiatry Research Group, Faculty of Medicine, Federal University of Ceará, Fortaleza, CE, Brazil \\ d Deakin University, IMPACT Strategic Research Centre, School of Medicine, Geelong, Australia \\ e Laboratory of Calcium Binding Proteins in the Central Nervous System, Department of Biochemistry, Federal University of Rio Grande do Sul, Porto Alegre, \\ Brazil \\ ${ }^{\mathrm{f}}$ Department of Neurosciences, University of Padova, Padova, Italy \\ ${ }^{g}$ National Health Care System, Padova Local Unit ULSS 17, Italy \\ ${ }^{\mathrm{h}}$ Institute for Clinical Research and Education in Medicine, I.R.E.M., Padua, Italy \\ ${ }^{i}$ Health, Social Care and Education, Anglia Ruskin University, Chelmsford, United Kingdom \\ ${ }^{j}$ Geriatrics Division, Department of Medicine-DIMED, University of Padova, Italy \\ ${ }^{\mathrm{k}}$ Institute of Clinical Research and Education in Medicine (IREM), Padova, Italy \\ ${ }^{1}$ Physiotherapy Department, South London and Maudsley NHS Foundation Trust, Denmark Hill, London SE5 8AZ, United Kingdom \\ ${ }^{\mathrm{m}}$ Health Service and Population Research Department, Institute of Psychiatry, Psychology and Neuroscience, King's College London, De Crespigny Park, \\ London Box SE5 8AF, United Kingdom
}

\section{A R T I C L E I N F O}

\section{Article history:}

Received 13 November 2016

Accepted 10 January 2017

\section{Keywords:}

Frailty

Frail

Oxidative stress

Anti-oxidant

\begin{abstract}
A B S T R A C T
Objective: Oxidative stress (OS) is associated with accelerated aging. Previous studies have suggested a possible relationship between OS and frailty but this association remains unclear. We conducted a systematic review to investigate potential interactions between OS and frailty.

Methods: A systematic literature search of original reports providing data on 'OS and antioxidant' parameters and frailty was carried out across major electronic databases from inception until May 2016. Cross-sectional/case control and longitudinal studies reporting data on the association between frailty and anti-oxidants-OS biomarkers were considered for inclusion. Results were summarized with a synthesis based on the best evidence.

Results: From 1856 hits, 8 studies (cross-sectional/case control) were included ( $\mathrm{N}=6349$; mean age of $75 \pm 12$ years; $56.4 \%$ females). Overall, there were $588(=9.3 \%)$ frail, 3036 pre-frail $(=47.8 \%), 40(=0.6 \%)$ pre-frail/robust, and $2685(=42.3 \%)$ robust subjects. Six cross-sectional/case control studies demonstrated that frailty was associated with an increase in peripheral OS biomarkers, including lipoprotein phospholipase A2 (1 study), isoprostanes ( 2 studies), malonaldehyde ( 2 studies), 8-hydroxy-20-deoxyguanosine (2 studies), derivate of reactive oxygen metabolites (2 studies), oxidized glutathione/glutathione (1 study), 4-hydroxy-2,3-nonenal ( 1 study), and protein carbonylation levels (1 study). In addition, preliminary evidence points to lower anti-oxidant parameters (vitamin C, E, $\alpha$-tocopherol, biological anti-oxidant potential, total thiol levels) in frailty.

Conclusion: Frailty and pre-frailty appear to be associated with higher OS and possibly lower anti-oxidant parameters. However, due to the cross-sectional design, it is not possible to disentangle the directionality of the relationships observed. Thus, future high-quality and in particular longitudinal research is required to confirm or refute these relationships and to further elucidate pathophysiological mechanisms.
\end{abstract}

(c) 2017 Elsevier B.V. All rights reserved.

\footnotetext{
* Corresponding author at: Physiotherapy Department, South London and Maudsley NHS Foundation Trust, Denmark Hill, London SE5 8AZ, United Kingdom.

E-mail address: Brendon.stubbs@kcl.ac.uk (B. Stubbs).
} 


\section{Contents}

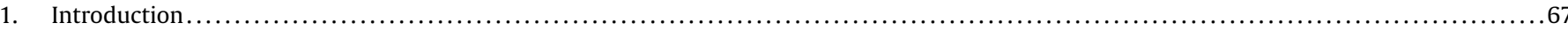

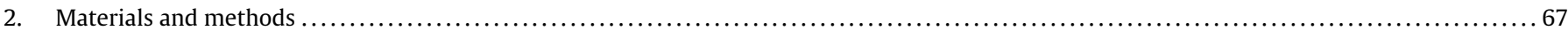

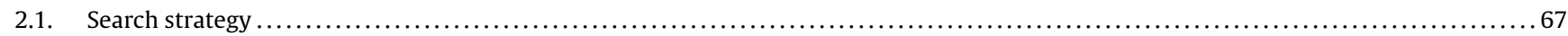

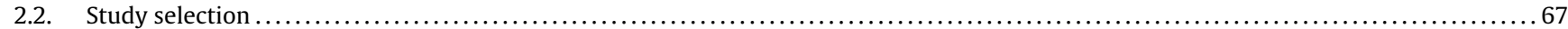

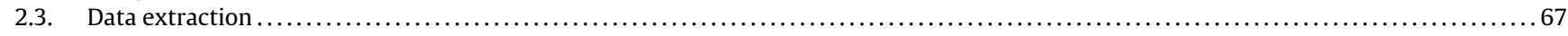

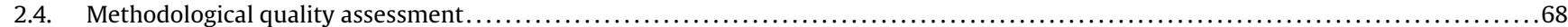

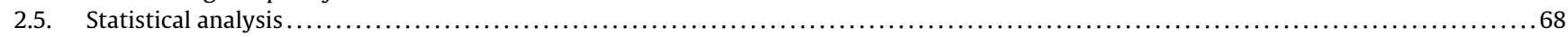

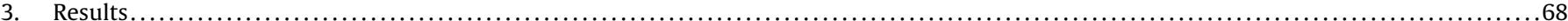

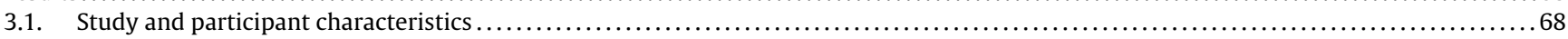

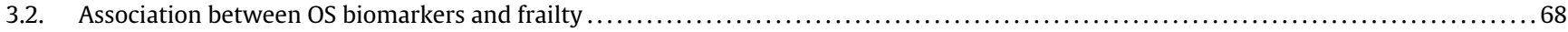

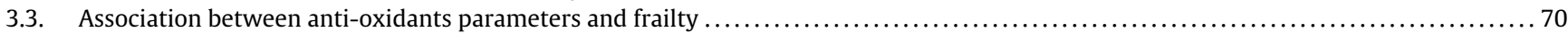

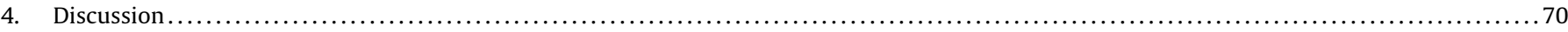

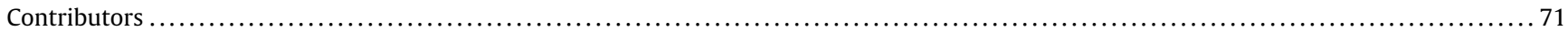

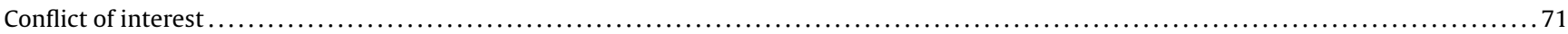

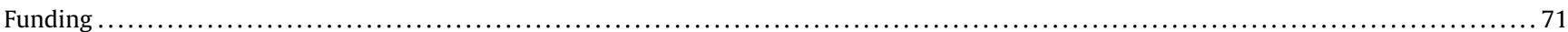

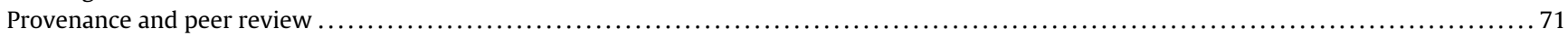

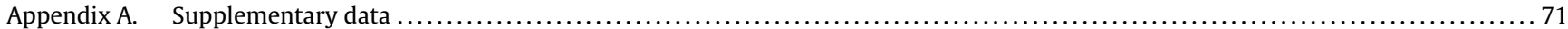

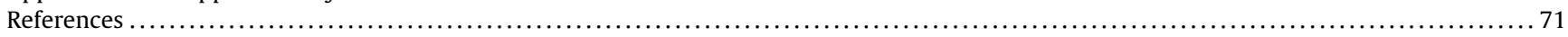

\section{Introduction}

Whilst the trajectory of aging can differ among older people [1], there is general agreement that aging is associated with an accumulation of cellular damage [2]. The pathophysiological changes associated with aging can lead to mitochondrial dysfunction, failure of tissue repair mechanisms, accelerated cellular senescence, in addition to a reduction in tissue homeostasis, which may increase the risk of organ failure and mortality [3]. One of the most important factors that may increase cellular aging is oxidative stress (OS) [4]. During the aging process the balance between the cellular antioxidant defence system and toxic effects due to OS may deteriorate [5]. Studies have reported that reactive oxygen species (ROS) could play a pivotal role in aging, and also in several age-related diseases such as sarcopenia, cerebrovascular, and neurodegenerative diseases [5].

In recent years, an accumulating body of evidence has suggested that OS and inflammatory changes might play a role in the development of frailty, which is another common age-related clinical syndrome [6,7]. Frailty is defined as "a state of increased vulnerability to stressors that results from decreased physiologic reserve in multiple organ systems causing limited capacity to maintain homeostasis" [8]. Frailty is associated with several deleterious outcomes, including a higher rate of hospitalization, depression, falls, disability and mortality in older adults [9]. The main features of frailty traditionally include low physical activity levels, slowness in motor performance, and weakness, which may occur due to a loss of skeletal muscle mass and functioning [8-10]. Furthermore, OS might lead to an activation of apoptotic pathways leading to cellular damage, aberrations in the expression of many transcription factors responsible for shifting protein synthesis to protein degradation, a decline in mitochondrial function, and an impairment of repair mechanisms $[2,11]$. These interacting pathways may contribute to the detrimental effects of OS on muscles, bones, and the immune system [12]. Loss of muscle mass and strength may reduce physical activity and thereby contribute to frailty [13].

A number of previous individual studies have suggested a possible relationship between OS and frailty $[14,15]$, but this relationship remains unclear. Therefore, we conducted a systematic review to determine the potential association between OS biomarkers and frailty. Our priori hypothesis was that frailty could be associated with higher peripheral levels of reactive oxygen species biomarkers and with lower levels of antioxidants, resulting in increased OS.

\section{Materials and methods}

This systematic review was conducted following the Preferred Reporting Items for Systematic Reviews and Meta-Analyses (PRISMA) [16]. An a priori unpublished protocol was followed [17].

\subsection{Search strategy}

Two investigators (PS, BS) independently conducted an electronic literature search using EMBASE, PubMed and Scopus with no language restrictions. The databases were searched from inception until 05/01/2016 for studies investigating the relationship between OS and frailty. Any inconsistencies were resolved by consensus with a third author (NV). The search terms used in Pubmed were (frailty OR frail) AND (oxidative stress OR oxidative injury OR oxidative damage OR anti-oxidants OR Reactive oxygen species OR Free radical OR redox balance). Conference abstracts were also considered.

\subsection{Study selection}

Included studies were those that [1] reported on peripheral levels of OS related biomarkers (reactive oxygen species related and anti-oxidants parameters) as a function of frailty status [2]; used a validated and standardized method for assessing frailty (e.g. those suggested by Fried et al.) [18]; and [3] included a control group (pre-frail and robust as separate entities or together). Studies were excluded if they [1] did not use clear diagnostic criteria for frailty or used only one item for its diagnosis (e.g. low gait speed) [2], animal or in vitro research [3], case reports [4], did not measure or did not report serum OS biomarkers levels or anti-oxidant parameters.

\subsection{Data extraction}

Two authors (BS, PS) independently extracted data from the selected studies in a standardized Microsoft Excel spreadsheet. Any disagreement was resolved through discussion with a third author (NV). The following information was extracted: (i) characteristics of the study population (e.g. sample size, demographics, country in which the study was performed); (ii) setting in which the study was performed; (iii) diagnostic criteria for frailty; (iv) OS parameters assessed with corresponding assays; ( $v$ ) demographic characteristics (mean age and percentage of women) and mean body mass index (BMI) according to frailty status. 


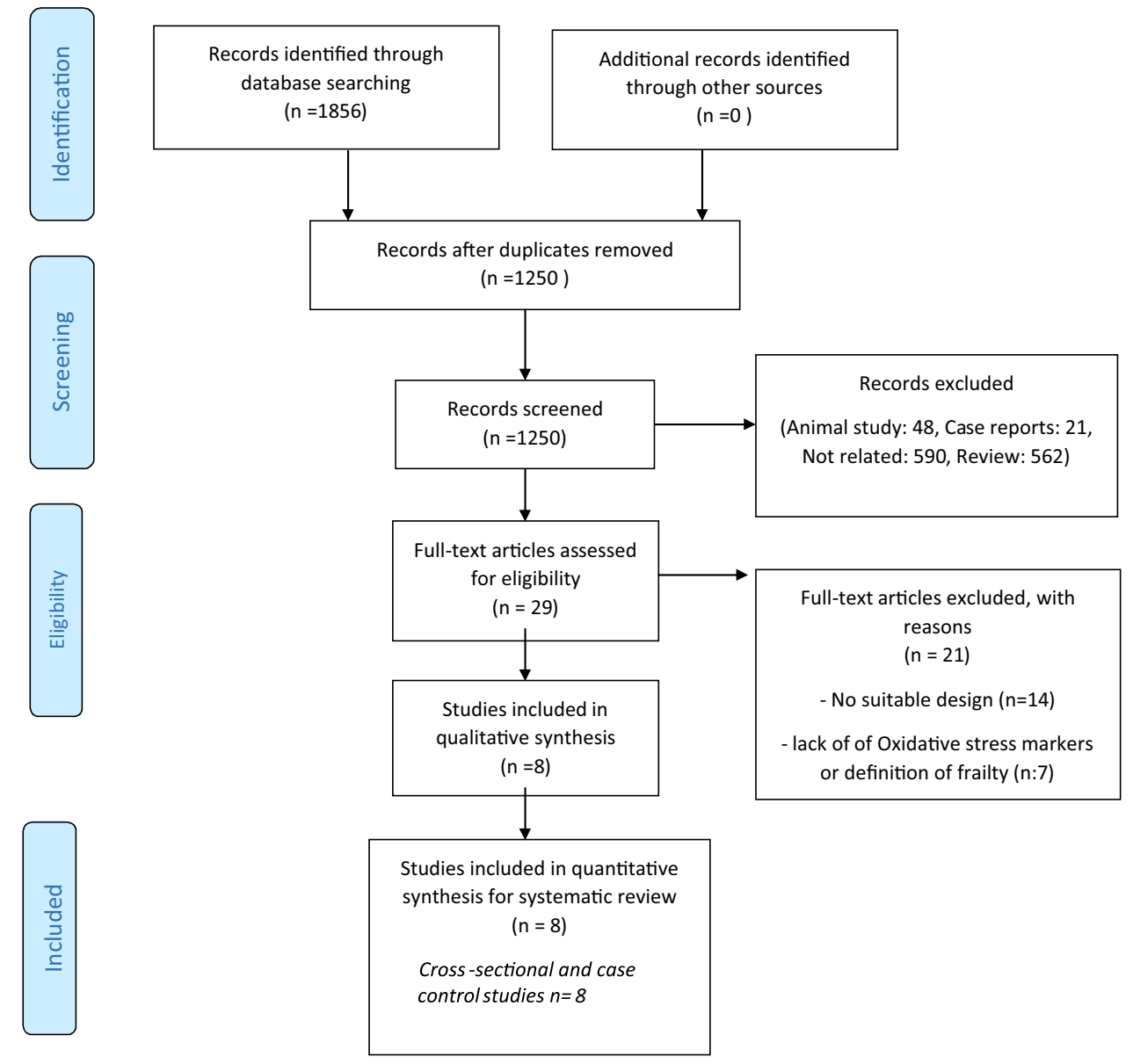

Fig. 1. Prisma search results.

\subsection{Methodological quality assessment}

Study quality was assessed by two investigators (PS, BS), whilst a third reviewer was available for mediation (NV). For cross-sectional and case control studies, the Newcastle-Ottawa Scale (NOS) was used to assess study quality. The NOS assigns a maximum of 9 points based on three quality parameters: selection, comparability, and outcome [19].

\subsection{Statistical analysis}

Due to the paucity and heterogeneity in outcomes and study samples, the findings of this review are summarized in a best evidence synthesis.

\section{Results}

The search identified 1250 potentially eligible studies. After excluding 1221 manuscripts through title/abstract screening, 29 full-text articles were examined and 8 studies [14,15,20-25] were included in this systematic review (Fig. 1).

\subsection{Study and participant characteristics}

Studies and participant characteristics are summarized in Table 1 . The 8 studies $[14,15,20-25]$ included a total of 6349 participants with a mean age of $75 \pm 12$ years and mainly women $(=56.4 \%)$. Overall, there were 588 (=9.3\%) frail, 3036 pre-frail $(=47.8 \%)$ and $2685(=42.3 \%)$ robust, and $40(=0.6 \%)$ pre-frail/robust subjects. All included studies were a cross-sectional/case-control design.
All included studies defined frailty using a modified version of Fried et al. [18] except for one study [22] in which the Rothman criteria [26] were used as a definition of frailty.

The majority of the studies was conducted among communitydwelling older adults (4 studies; $=57.1 \%$ ) and in Europe $(n=4)$, followed by Asia $(n=2)$ and America $(n=2)$ (Table 1$)$. The quality of the studies, assessed through NOS, was generally good with a median score of 7 (range: 6-9) (Supplementary Table 1).

Frail participants were older $(76.7 \pm 9.8$ years $)$, more frequently females $(=61.7 \%)$ and exhibited higher BMI $(=28.8 \pm 6.7 \mathrm{~kg} / \mathrm{m} 2)$ than pre-frail (73.1 \pm 9.1 years; \% of females: 56.6 ; BMI: $27.3 \pm 7.3 \mathrm{~kg} / \mathrm{m} 2)$ and robust $(68.9 \pm 7.8$ years; \% of females: 49.2; BMI: $26.5 \pm 8.1 \mathrm{~kg} / \mathrm{m} 2$ ) elders (Table 1 ).

\subsection{Association between OS biomarkers and frailty}

As shown in Table 2, seven studies [14,15,21,22-25] reported data for peripheral OS biomarkers. Only one study did not find any significant difference between frail and robust groups regarding paraoxonase-1 (PON-1) and Malonaldehyde (MDA) levels $(p>0.05)$ [22], but another study found higher MDA levels among frail elders $(p<0.01)$ [24]. All included studies, except one [22], reported that higher OS biomarkers were significantly associated with frailty [14,15,21,23-25]. Oxidative stress biomarkers assayed across studies included lipoprotein phospholipase A2 (LpPLA2), isoprostanes, MDA, 4-hydroxy-2,3-nonenal (HNE), 8-hydroxy-20deoxyguanosine, derivate of reactive oxygen metabolites (d-ROM), Oxidized Glutathione/Glutathione (GSSG/GSH), and protein carbonylation levels $(\mathrm{p}<0.05)$. The derivate of reactive oxygen 
Table 1

Descriptive findings of the studies included.

\begin{tabular}{|c|c|c|c|c|c|c|c|c|c|}
\hline Author,year (Country) & Setting & Participants & Mean age & Mean BMI & \% Female & $\begin{array}{l}\text { Diagnostic criteria } \\
\text { for frailty }\end{array}$ & $\begin{array}{l}\text { OS parameters } \\
\text { assessed }\end{array}$ & $\begin{array}{l}\text { Methods of } \\
\text { measurement }\end{array}$ & $\begin{array}{l}\text { NOS Score } \\
\text { Quality }\end{array}$ \\
\hline Ble, 2006 (Italy) [20] & Community & $\begin{array}{l}\text { Frail:54 } \\
\text { Pre-frail:313 } \\
\text { Robust:460 }\end{array}$ & NA & NA & NA & Fried & Plasma vitamin E & $\begin{array}{l}\text { High-performance } \\
\text { liquid } \\
\text { chromatography }\end{array}$ & 7 \\
\hline Liu, 2016 (USA) [21] & Community & $\begin{array}{l}\text { Frail:142 } \\
\text { Pre-frail:864 } \\
\text { Robust:913 }\end{array}$ & $\begin{array}{l}77 \pm 6 \\
72 \pm 7 \\
69 \pm 6\end{array}$ & $\begin{array}{l}29.6 \pm 7.0 \\
28.8 \pm 5.3 \\
27.3 \pm 4.5\end{array}$ & $\begin{array}{l}54 \\
57 \\
51\end{array}$ & Fried & $\begin{array}{l}\text { LpPLA2, } \\
\text { isoprostanes }\end{array}$ & ELISA & 9 \\
\hline Goulet, 2009 (Canada) [22] & $\begin{array}{l}\text { Community } \\
\text { and } \\
\text { Inpatients }\end{array}$ & $\begin{array}{l}\text { Frail: } 33 \\
\text { Pre-frail/Robust: } \\
21\end{array}$ & $\begin{array}{l}82 \pm 5 \\
79 \pm 5\end{array}$ & $\begin{array}{l}27.8 \pm 3.8 \\
27.1 \pm 1.2\end{array}$ & $\begin{array}{l}73.0 \\
52.3\end{array}$ & Rothman criteria & $\begin{array}{l}\text { Malondialdehyde, } \\
\text { Paraoxonase-1, } \\
\text { antioxidant } \\
\text { capacity (vitamin C, } \\
\text { E) }\end{array}$ & $\begin{array}{l}\text { Spectrophotometer/ } \\
\text { fluorimetric-liquid } \\
\text { chromatographic }\end{array}$ & 7 \\
\hline Serviddio, 2009 (Italy) [23] & Outpatients & $\begin{array}{l}\text { Frail:43 } \\
\text { Prefrail/Robust:19 }\end{array}$ & NA & NA & NA & Fried & $\begin{array}{l}\text { Glutathione, } \\
\text { Oxidized } \\
\text { Glutathione, } \\
\text { Malonaldehyde, } \\
\text { 4-hydroxy-2,3- } \\
\text { nonenal }\end{array}$ & Western Blot & 8 \\
\hline Wu, 2009 (Taiwan) [15] & $\begin{array}{l}\text { Community } \\
\text { and } \\
\text { Outpatients }\end{array}$ & $\begin{array}{l}\text { Frail:21 } \\
\text { Pre-frail:56 } \\
\text { Robust:13 }\end{array}$ & $\begin{array}{l}79.9 \pm 5.8 \\
76.8 \pm 5.8 \\
73.1 \pm 5.3\end{array}$ & NA & NA & Fried & $\begin{array}{l}\text { 8-hydroxy-20- } \\
\text { deoxyguanosine }\end{array}$ & ELISA & 6 \\
\hline Saum, 2015 (Germany) [14] & Community & $\begin{array}{l}\text { Frail:210 } \\
\text { Pre-frail:1463 } \\
\text { Robust:845 }\end{array}$ & $\begin{array}{l}73.7 \pm 6.0 \\
70.3 \pm 6.2 \\
67.8 \pm 5.8\end{array}$ & $\begin{array}{l}30.2 \pm 6.2 \\
28.7 \pm 4.7 \\
28.3 \pm 4.4\end{array}$ & $\begin{array}{l}64.8 \\
56.1 \\
43.4\end{array}$ & Fried & $\begin{array}{l}\text { derivate of reactive } \\
\text { oxygen } \\
\text { metabolites, } \\
\text { biological } \\
\text { anti-oxidant } \\
\text { potential, total } \\
\text { thiol levels }\end{array}$ & autoanalyzer & 9 \\
\hline Ingleís, 2014 (Spain) [24] & Community & $\begin{array}{l}\text { Frail:51 } \\
\text { Pre-frail:278 } \\
\text { Robust:410 }\end{array}$ & $\begin{array}{l}78.8 \pm 6.0 \\
73.8 \pm 4.7 \\
72.4 \pm 4.2\end{array}$ & $\begin{array}{l}30.0 \pm 5.5 \\
29.5 \pm 4.9 \\
29.7 \pm 5.0\end{array}$ & $\begin{array}{l}66.7 \\
57.5 \\
57.8\end{array}$ & Fried & $\begin{array}{l}\text { MDA and protein } \\
\text { carbonylation }\end{array}$ & $\begin{array}{l}\text { High-Performance } \\
\text { Liquid } \\
\text { Chromatography, } \\
\text { Western } \\
\text { Blotting }\end{array}$ & 7 \\
\hline Namioka, 2016 (Japan) [25] & Outpatients & $\begin{array}{l}\text { Frail:34 } \\
\text { Pre-frail:62 } \\
\text { Robust:44 }\end{array}$ & $\begin{array}{l}82.3 \pm 6.1 \\
80.5 \pm 4.9 \\
78.2 \pm 6.0\end{array}$ & $\begin{array}{l}23.5 \pm 3.8 \\
22.3 \pm 3.1 \\
22.7 \pm 3.0\end{array}$ & $\begin{array}{l}67.6 \\
64.5 \\
43.1\end{array}$ & Fried & $\begin{array}{l}\text { Diacron reactive } \\
\text { oxygen metabolite, } \\
\text { 8-Hydroxy-2 } \\
\text {-deoxyguanosine, } \\
\text { 8-isoprostane, } \\
\text { biological } \\
\text { anti-oxidant } \\
\text { potential }\end{array}$ & $\begin{array}{l}\text { ELISA, } \\
\text { high-performance } \\
\text { liquid } \\
\text { chromatography }\end{array}$ & 9 \\
\hline Total & $\begin{array}{l}\text { 4: community- } \\
\text { dwelling; 2: } \\
\text { Outpatients; 1: } \\
\text { both community- } \\
\text { dwelling and } \\
\text { inpatients; 1: both } \\
\text { community and } \\
\text { Outpatients }\end{array}$ & $\begin{array}{l}\text { Frail: } 588 \\
\text { Pre-frail: } 3036 \\
\text { Robust: } 2685 \\
\text { Pre-frail/robust:40 } \\
\text { Total: } 6349\end{array}$ & $\begin{array}{l}\text { Frail: } \\
76.7 \pm 9.8 \\
\text { Pre-frail: } \\
73.1 \pm 9.1 \\
\text { Robust: } \\
68.9 \pm 7.8 \\
\text { Pre-frail/Robust: } \\
79 \pm 5\end{array}$ & $\begin{array}{l}\text { Frail: } \\
\text { 28.8 } \pm 6.7 \\
\text { Pre-frail: } \\
27.3 \pm 7.3 \\
\text { Robust: } \\
\text { 26.5 } \pm \mathbf{8 . 1} \\
\text { Pre-frail/Robust: } \\
27.1 \pm \mathbf{1 . 2}\end{array}$ & $\begin{array}{l}61.7 \\
56.6 \\
49.2\end{array}$ & $\begin{array}{l}\text { 7: Fried's criteria } \\
\text { 1: Rothman }\end{array}$ & & & $\begin{array}{l}\text { Median:7 } \\
(6-9)\end{array}$ \\
\hline
\end{tabular}

BMI: Body Mass Index; ELISA: Enzyme-Linked Immuno Sorbent Assay; LpPLA2: Lipoprotein-associated phospholipase A2; MDA: Malonaldehyde; NA: Not available, NOS = Newcastle Ottawa Scale. 
Table 2

Findings of the studies investigating oxidative biomarkers.

\begin{tabular}{|c|c|c|c|c|}
\hline Study & Oxidative biomarkers & Robust & Pre-frail & Frail \\
\hline Liu [21] & $\begin{array}{l}\text { LpPLA2 mass }(\mathrm{ng} / \mathrm{mL}) \\
\text { LpPLA2 activity }(\mathrm{nm} / \mathrm{mL} / \mathrm{min}) \\
\text { Isoprostanes }(\mathrm{mg} / \mathrm{L})\end{array}$ & $\begin{array}{l}199(168,228)^{\mathrm{a}} \\
139(119,166)^{\mathrm{a}} \\
9.5(7.1,12.8)^{\mathrm{a}}\end{array}$ & $\begin{array}{l}199(172,229)^{\mathrm{a},{ }^{*}} \\
137(115,160)^{\mathrm{a}, *} \\
10.2(7.60,14.30)^{\mathrm{a}, *}\end{array}$ & $\begin{array}{l}210(183,237)^{\mathrm{a},{ }^{*}} \\
139(119,166)^{\mathrm{a}, *} \\
11.5(8.50,15.40)^{\mathrm{a}, *}\end{array}$ \\
\hline Goulet [22] & $\begin{array}{l}\mathrm{PON}-1(\mu \mathrm{mol} / \mathrm{L}) \\
\operatorname{MDA}(\mu \mathrm{mol} / \mathrm{L})\end{array}$ & $\begin{array}{l}1.64 \pm 1.04(\text { robust }+ \text { pre-frail }) \\
1.29 \pm 0.41(\text { robust }+ \text { pre-frail })\end{array}$ & $\begin{array}{l}\text { NA } \\
\text { NA }\end{array}$ & $\begin{array}{l}\text { FL: } 1.33 \pm 1.01 \mathrm{FO}: 0.91 \pm 0.91 \\
\text { FL: } 1.17 \pm 0.36 \mathrm{FO}: 1.12 \pm 0.31\end{array}$ \\
\hline $\begin{array}{l}\text { Wu [15] } \\
\text { Saum [14] } \\
\text { Ingleís [24] }\end{array}$ & $\begin{array}{l}\text { 8-hydroxy-20-deoxyguanosine (mg/L) } \\
\text { d-ROM (U.CARR) } \\
\text { MDA ( } \mu \mathrm{M}) \\
\text { Protein carbonylation levels (arbitrary units) }\end{array}$ & $\begin{array}{l}1.0(0.5-5.3)^{\mathrm{b}} \\
339.6(296.8-385.4)^{\mathrm{b}} \\
2.11 \pm 1.80 \\
64.36 \pm 14.29\end{array}$ & $\begin{array}{l}2.3(0.5-8.1)^{\mathrm{b}} \\
354.8(310.3-398.3)^{\mathrm{b}} \\
2.43 \pm 2.26 \\
75.01 \pm 15.51^{*}\end{array}$ & $\begin{array}{l}2.5(1.5-6.2)^{\mathrm{b},{ }^{*}} \\
371.6(318.5-420.5)^{\mathrm{b}, * *} \\
3.28 \pm 2.45^{*} \\
77.60 \pm 15.60^{*}\end{array}$ \\
\hline Namioka [25] & $\begin{array}{l}\text { Urine 8-OHdG (ng/mg Cre) } \\
\text { 8-isoprostane (pg/mg Cre) } \\
\text { Plasma dROM (U.CARR) }\end{array}$ & $\begin{array}{l}3.90 \pm 1.67 \\
235 \pm 98 \\
418 \pm 65\end{array}$ & $\begin{array}{l}5.44 \pm 2.70^{* *} \\
305 \pm 126^{*} \\
450 \pm 70^{*}\end{array}$ & $\begin{array}{l}5.39 \pm 2.23^{* *} \\
342 \pm 175^{* * *} \\
485 \pm 86^{* * *}\end{array}$ \\
\hline
\end{tabular}

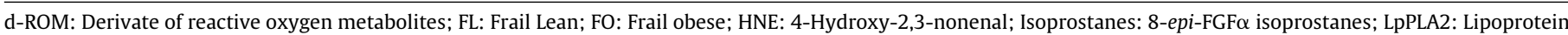
phospholipase A2; MDA: Malonaldehyde; NA: Not available; PON-1: Paraoxonase-1.

a Median (25th percentile, 75th percentile).

b Median (range).

* For $p$-value $<0.05$ compared with robust participants.

** For $\mathrm{p}<0.001$.

${ }^{* * *}$ For $p$-value $<0.0001$.

Table 3

Findings of the studies investigating anti-oxidants parameters.

\begin{tabular}{|c|c|c|c|c|}
\hline Study & Anti-oxidant Parameters & Robust & Pre-frail & Frail \\
\hline Ble [20] & Plasma vitamin $\mathrm{E} \mu \mathrm{mol} / \mathrm{L}$ & 26.7 & 28.6 & $29.6^{*}$ \\
\hline \multirow{2}{*}{ Goulet [22] } & vitamin $\mathrm{C}\left(\mu \mathrm{mol} \mathrm{L}^{-1}\right)$ & $36.4 \pm 20.5$ (robust + pre-frail) & NA & $43.8 \pm 28.8$ \\
\hline & $\alpha$-Tocopherol $\left(\mu \mathrm{mol} \mathrm{L}^{-1}\right)$ & $17.8 \pm 13.4$ (robust + pre-frail) & NA & FL: $20.2 \pm 16.9 F O: 20.8 \pm 16.6$ \\
\hline \multirow[t]{2}{*}{ Saum [14] } & $\mathrm{BAP}(\mu \mathrm{mol} / \mathrm{L})$ & $2,567.0^{\mathrm{a}}(2,454.6-2,684.3)$ & $2,573.8^{\mathrm{a}}(2,448.9-2698.9)$ & $2,609.7^{\mathrm{a}}(2,449.3-2,728.8)$ \\
\hline & $\operatorname{TTL}(\mu \mathrm{mol} / \mathrm{L})$ & $342.1^{\mathrm{a}}(294.0-386.9)$ & $327.6^{\mathrm{a}}(277.2-377.9)$ & $302.9^{\mathrm{a},{ }^{, *}}(255.8-355.5)$ \\
\hline Namioka, 2016 [25] & $\mathrm{BAP}(\mu \mathrm{mol} / \mathrm{L})$ & $2599 \pm 627$ & $2501 \pm 586$ & $2390 \pm 680^{*}$ \\
\hline
\end{tabular}

BAP: Biological Anti-Oxidant Potential; FL: Frail Lean; FO: Frail obese; TTL: Total Thiol Levels. ${ }^{* * *}$ For $p$-value $<0.0001$.

a Median (range).

* For $p$-value $<0.05$ compared with robust.

For $\mathrm{p}<0.001$.

metabolites (d-ROM) was evaluated in two studies, d-ROM levels were higher in frail/prefrail compare the robust elderly groups $(p<0.01)[14,25]$. Furthermore, levels of isoprostanes were increased in both frail and pre-frail elders in other two studies $(p<0.05)[21,25]$. Finally, higher levels of 8-hydroxydeoxyguanosine (8-OHdG), which were measured in urine in one and in blood in another study, were associated with frail/pre-frail status $(\mathrm{p}<0.05)[15,25]$ (Table 2$)$.

One study reported a statistically higher levels of OS among people with frailty versus people without frailty $(\mathrm{p}<0.01)$, but precise values are not reported in the paper [23].

\subsection{Association between anti-oxidants parameters and frailty}

As shown in Table 3, four studies [14,20,22,25] reported data regarding anti-oxidant parameters. One study reported that levels of vitamin $\mathrm{E}$ decreased gradually from robust to frail subjects $(\mathrm{p}<0.05)$ [20]. Another study did not find any significant difference between frail and pre-frail/robust groups in $\alpha$-tocopherol and vitamin C serum levels [22] $(p>0.05)$. Two studies evaluated biological anti-oxidant potential (BAP) [14,25]. One found that BAP levels were significantly lower in the frail participants compared to those who were pre-frail or robust $(p<0.05)[25]$. However, another study did not find any statistical significant difference for BAP between those with frailty and people who were robust $(p>0.05)$ [14]. In one study, a significant association with frailty was observed for Total Thiol Levels (TTL) $(p<0.0001)$ [14].

\section{Discussion}

In this systematic review, including eight studies and a total of 6349 participants, we summarized the current evidence regarding the relationship between frailty and OS parameters. Overall, available data suggest that in cross-sectional and case control studies, there is evidence of higher levels of peripheral OS biomarkers and lower anti-oxidant parameters among frail older adults. One study did not find any such relationship and the reasons for may be due to the inclusion of pre-frail participants in the comparison group and that this study had a small sample size [22].

Aging is influenced by multiple factors, including OS, inflammation, glycation, telomere shortening, mutations, degradation of proteins and enzymes, and a progressive damage of the structure and function of biomolecules, cells, and organs [27]. The deteriorations related to OS rank first among causes of aging [4], and may lead to development of age-related diseases, such as macular degeneration, sarcopenia, cerebrovascular diseases, Alzheimer's disease (AD), Parkinson's disease, cancer, and consequently mortality [5,28], although the direction of this relationship is motive of debate. Furthermore, anti-oxidants have been proposed as novel therapeutic targets for several aging-associated diseases, due in part to their cardio-protective, chemotherapeutic, and neuroprotective effects [29]. Nowadays, effects of both OS and anti-oxidant parameters on the initiation and progression of age-related diseases remain unclear; however, clinical and experimental studies have intensively investigated this topic [4,5,27-29].

In recent years it is thought that OS also may be associated with frailty, which develops slowly in a stepwise process, and 
may be precipitated by acute events [30], but the relationship between OS and frailty is complex since both linearly increase with advancing age. Both higher OS in the periphery and frailty are accompanied by several negative outcomes, such as higher mortality and multi-morbidity $[9,28]$. Our systematic review suggests that frailty is associated with higher OS and lower anti-oxidant peripheral parameters. The relationship between OS and frailty could be explained by several hypotheses. First, OS may lead to musculoskeletal system damage due to the fact that OS increase intracellular calcium promoting proteasomal activity and accelerating muscle breakdown, and ROS may trigger the apoptosis of murine skeletal muscle, and decrease myoblast proliferation $[12,31]$. These factors may contribute to a decline in muscle function and strength. Loss of muscle mass and strength can directly reduce physical activity levels. Low physical activity is one of the hallmarks of frailty [18], and has been consistently reported to significantly increase OS in both animal models and humans [13,32]. Therefore, a vicious circle may occur between OS and frailty. Second, OS may also contribute to immune activation through generating oxidized cellular components [15]. Frail people have a significant reduction in the function of the innate immune system, T-cell activity, the production of antibodies, and an increase in mitochondrial activity by means of OS products [7,33]. In addition, predominantly inflammatory cytokines may influence frailty status either directly by promoting protein degradation, or indirectly by affecting important metabolic pathways [34]. Third, frail and pre-frail participants have a higher prevalence of various medical disorders, including cardiovascular diseases, stroke, dementia and diabetes mellitus, all of which are both strongly associated with frailty and could also increase the generation of OS products $[5,28]$. These chronic diseases, arising mainly in later life, may increase resting metabolic rate in order to maintain cellular homeostasis, which drive the generation of ROS by dysregulated mitochondria, ultimately leading to homeostatic deregulation and then loss of muscle strength [14]. Finally, frail and pre-frail people are generally more obese than robust participants and obesity is highly associated with systemic OS [35]. This hypothesis is also consistent with the fact that an increase in adiposity may affect muscle mass and walking ability among frail subjects [36]. Clearly, future longitudinal work is required to disentangle the relationships we observed and elucidate potential pathophysiological mechanisms.

Putative beneficial effects of antioxidants on frailty are not surprising when the aforementioned mechanisms are considered. Previous studies reported that there is a strong correlation of plasma concentrations of antioxidants and physical performance and strength among the elderly [37], and that the supplementation of antioxidants may improve muscle mass, grip strength, and mitochondrial dynamics in skeletal systems [38]. Moreover, elderly people with lower peripheral antioxidant levels are more vulnerable to disability and mortality over a 5-year follow-up period [39]. The findings of our systematic review may provide a further impetus to test antioxidants as novel treatment targets to prevent or manage frailty.

Although this study has expanded the knowledge on this topic, it has a number of limitations, which are reflected by the available literature. First, it should be kept noted that OS may increase exponentially during the aging process and since the data in the current study are cross sectional, no certainty can be made regarding the direction of the relationships observed. However, we attempted to try and disentangle the relationship of OS and frailty by stratifying the results according to frailty status (frail, pre frail and robust). Another limitation is that due to the heterogeneity of the studies included, a meta-analysis could not be performed. Moreover, some potential confounders, such as medical comorbidities, and drugs, which may effect on frailty, could not be systematically considered. In addition, the relationdhip between OS and frailty may be bidirectional, thus neccessitating future longitudinal research to disentangle the directionality of the relationships observed. Another limitation is that most studies defined frailty according to Fried et al. which focusses on physical frailty, and does not take into consideration other relevant features (e.g., cognitive frailty).

In conclusion, our review suggest there is some suggestive evidence that frailty and pre-frailty are associated with higher peripheral OS and lower anti-oxidant parameters. However, future high-quality prospective research is warranted to confirm these findings.

\section{Contributors}

PS, BS and NV conceived the study, conducted the searches and wrote the manuscript.

All co-authors provided critical comments and approved the final version.

\section{Conflict of interest}

The authors declare that they have no conflict of interest.

\section{Funding}

No funding was received for this review.

\section{Provenance and peer review}

This article has undergone peer review.

\section{Appendix A. Supplementary data}

Supplementary data associated with this article can be found, in the online version, at http://dx.doi.org/10.1016/j.maturitas.2017. 01.006 .

\section{References}

[1] Hui-Chuan Hsu, Bobby L. Jones, Multiple trajectories of successful aging of older and younger cohorts, Gerontologist 52 (December (6)) (2012) 843-856.

[2] M. Pinto, C.T. Moraes, Mechanisms linking mtDNA damage and aging, Free Radic. Biol. Med. 85 (August) (2015) 250-258.

[3] Y.C. Long, et al., The biochemistry and cell biology of aging: metabolic regulation through mitochondrial signaling, Am. J. Physiol. Endocrinol. Metab. 306 (6) (2014) E581-E591.

[4] E.P. Crowe, F. Tuzer, B.D. Gregory, G. Donahue, S.J. Gosai, J. Cohen, Y.Y. Leung, E. Yetkin, R. Nativio, L.S. Wang, C. Sell, N.M. Bonini, S.L. Berger, F.B. Johnson, C. Torres, Changes in the transcriptome of human astrocytes accompanying oxidative stress-induced senescence, Front. Aging Neurosci. 8 (August) (2016) 208.

[5] M. Reinisalo, A. Kårlund, A. Koskela, K. Kaarniranta, R.O. Karjalainen, Polyphenol stilbenes molecular mechanisms of defence against oxidative stress and aging-related diseases, Oxid. Med. Cell. Longev. 2015 (2015) 340520.

[6] K.U. Saum, A.K. Dieffenbach, E.H. Jansen, B. Schöttker, B. Holleczek, K. Hauer $\mathrm{H}$. Brenner, Association between oxidative stress and frailty in an elderly German population: results from the ESTHER Cohort Study, Gerontology 61 (5) (2015) 407-415.

[7] P. Soysal, B. Stubbs, P. Lucato, et al., Inflammation and frailty in the elderly: a systematic review and meta-analysis, Ageing Res. Rev. 31 (November) (2016) $1-8$.

[8] A. Clegg, J. Young, S. Iliffe, M.O. Rikkert, K. Rockwood, Frailty in elderly people, Lancet 381 (9868) (2013) 752-762.

[9] M.T.E. Puts, Frailty Biological Risk Factors, Negative Consequences and Quality of Life. Ph.D. Dissertation, VU University Amsterdam, 2006 (p. 215).

[11] W.B. Ershler, A gripping reality: oxidative stress, inflammation, and the pathway to frailty, J. Appl. Physiol. (1985) 103 (2007) 3-5.

[12] F. Derbre, A. Gratas-Delamarche, M.C. Gomez-Cabrera, J. Vina, Inactivity-induced oxidative stress: a central role in age-related sarcopenia? Eur. J. Sports Sci. 14 (Suppl. 1) (2014) S98-S108.

[13] F. Agostini, L. Dalla Libera, J. Rittweger, et al., Effects of inactivity on human muscle glutathione synthesis by a double-tracer and single-biopsy approach, J. Physiol. 588 (2010) 5089-5104 
[14] K.U. Saum, A.K. Dieffenbach, E.H. Jansen, B. Schöttker, B. Holleczek, K. Hauer H. Brenner, Association between oxidative stress and frailty in an elderly German population: results from the ESTHER Cohort Study, Gerontology 61 (5) (2015) 407-415

[15] I.C. Wu, S.C. Shiesh, P.H. Kuo, X.Z. Lin, High oxidative stress is correlated with frailty in elderly Chinese, J. Am. Geriatr. Soc. 57 (September (9)) (2009) 1666-1671.

[16] A. Liberati, D.G. Altman, J. Tetzlaff, et al., The PRISMA statement for reporting systematic reviews and meta-analyses of studies that evaluate health care interventions: explanation and elaboration, PLoS Med. 6 (7) (2009) e1000100.

[17] D.F. Stroup, J.A. Berlin, S.C. Morton, I. Olkin, G.D. Williamson, D. Rennie, et al, Meta-analysis of observational studies in epidemiology: a proposal for reporting. Meta-analysis Of Observational Studies in Epidemiology (MOOSE) group, JAMA 283 (2000) 2008-2012.

[18] L.P. Fried, C.M. Tangen, J. Walston, A.B. Newman, C. Hirsch, J. Gottdiener, T. Seeman, R. Tracy, W.J. Kop, G. Burke, M.A. McBurnie, Frailty in older adults: evidence for a phenotype, J. Gerontol. Ser. A: Biol. Sci. Med. Sci. 56 (2001) M146-M156.

[19] G. Wells, B. Shea, D. O'Connell, J. Peterson, V. Welch, M. Losos, P. Tugwell, The Newcastle-Ottawa Scale (NOS) for Assessing the Quality If Nonrandomized Studies in Meta-Analyses, 2012, Available from: URL: http://www.ohri.ca/ programs/clinical_epidemiology/oxford.asp.

[20] A. Ble, A. Cherubini, S. Volpato, B. Bartali, J.D. Walston, B.G. Windham, S. Bandinelli, F. Lauretani, J.M. Guralnik, L. Ferrucci, Lower plasma vitamin E levels are associated with the frailty syndrome: the in CHIANTI Study, J. Gerontol. A: Biol. Sci. Med. Sci. 61 (March (3)) (2006) 278-283.

[21] C.K. Liu, A. Lyass, M.G. Larson, J.M. Massaro, N. Wang, R.B. D’Agostino Sr., E.J. Benjamin, J.M. Murabito, Biomarkers of oxidative stress are associated with frailty: the Framingham Offspring Study, Age (Dordr.) 38 (February (1)) (2016) 1.

[22] E.D. Goulet, A. Hassaine, I.J. Dionne, P. Gaudreau, A. Khalil, T. Fulop, B. Shatenstein, D. Tessier, J.A. Morais, Frailty in the elderly is associated with insulin resistance of glucose metabolism in the postabsorptive state only in the presence of increased abdominal fat, Exp. Gerontol. 44 (November (11)) (2009) 740-744.

[23] G. Serviddio, A.D. Romano, A. Greco, T. Rollo, F. Bellanti, E. Altomare, G Vendemiale, Frailty syndrome is associated with altered circulating redox balance and increased markers of oxidative stress, Int. J. Immunopathol. Pharmacol. 22 (July-September (3)) (2009) 819-827.

[24] M. Inglés, J. Gambini, J.A. Carnicero, F.J. García-García, L. Rodríguez-Mañas, G. Olaso-González, M. Dromant, C. Borrás, J. Viña, Oxidative stress is related to frailty, not to age or sex, in a geriatric population: lipid and protein oxidation as biomarkers of frailty, J. Am. Geriatr. Soc. 62 (July (7)) (2014) 1324-1328.
[25] N. Namioka, H. Hanyu, D. Hirose, H. Hatanaka, T. Sato, S. Shimizu, Oxidative stress and inflammation are associated with physical frailty in patients with Alzheimer's disease, Geriatr. Gerontol. Int. (2016), http://dx.doi.org/10.1111/ ggi.12804.

[26] M.D. Rothman, L. Leo-Summers, T.M. Gill, Prognostic significance of potential frailty criteria, J. Am. Geriatr. Soc. 56 (2008) 2211-2216.

[27] S.I. Liochev, Which is the most significant cause of aging? Antioxid. (Basel) 4 (December (4)) (2015) 793-810.

[28] R.S. Patel, N. Ghasemzadeh, D.J. Eapen, S. Sher, S. Arshad, Y.A. Ko, E. Veledar, H. Samady, A.M. Zafari, L. Sperling, V. Vaccarino, D.P. Jones, A.A. Quyyumi, Novel biomarker of oxidative stress is associated with risk of death in patients with Coronary artery disease, Circulation 133 (January (4)) (2016) 361-369.

[29] K.K. Abu-Amero, A.A. Kondkar, K.V. Chalam, Resveratrol and ophthalmic diseases, Nutrients 8 (April (4)) (2016) 200, http://dx.doi.org/10.3390/ nu8040200.

[30] K. Rockwood, A. Mitnitski, Frailty in relation to the accumulation of deficits, J. Gerontol. A: Biol. Sci. Med. Sci. 62 (2007) 722-727.

[31] F.X. Boittin, O. Petermann, C. Hirn, P. Mittaud, O.M. Dorchies, E. Roulet, U.T Ruegg, Ca2+-independent phospholipase A2 enhances store-operated Ca2+ entry in dystrophic skeletal muscle fibers, J. Cell Sci. 119 (2006) 3733-3742.

[32] M. Bar-Shai, E. Carmeli, P. Ljubuncic, A.Z. Reznick, Exercise and immobilization in aging animals: the involvement of oxidative stress and NF-kappaB activation, Free Radic. Biol. Med. 44 (2008) 202-214.

[33] H. Li, B. Manwani, S.X. Leng, Frailty, inflammation, and immunity, Aging Dis. 2 (2011) 466-473.

[34] P.O. Lang, J.P. Michel, D. Zekry, Frailty syndrome: a transitional state in a dynamic process, Gerontology 55 (5) (2009) 539-549.

[35] J.F. Keaney Jr., M.G. Larson, R.S. Vasan, P.W. Wilson, I. Lipinska, D. Corey, J.M. Massaro, P. Sutherland, J.A. Vita, E.J. Benjamin, Framingham Study, Obesity and systemic oxidative stress: clinical correlates of oxidative stress in the Framingham Study, Arterioscler. Thromb. Vasc. Biol. 23 (March (3)) (2003) 434-439.

[36] J. Woo, J. Leung, T. Kwok, BMI, body composition, and physical functioning in older adults, Obes. (Silver Spring) 15 (2007) 1886-1894.

[37] M. Cesari, M. Pahor, B. Bartali, A. Cherubini, B.W. Penninx, G.R. Williams, H. Atkinson, A. Martin, J.M. Guralnik, L. Ferrucci, Antioxidants and physical performance in elderly persons: the Invecchiare in Chianti (InCHIANTI) Study, Am. J. Clin. Nutr. 79 (February (2)) (2004) 289-294.

[38] M. van Dijk, F.J. Dijk, A. Bunschoten, D. A. van Dartel, K. van Norren, S. Walrand, M. Jourdan, S. Verlaan, Y. Luiking, Improved muscle function and quality after diet intervention with leucine-enriched whey and antioxidants in antioxidant deficient aged mice, Oncotarget 7 (April (14)) (2016) 17338-17355.

[39] J. Walston, Q. Xue, R.D. Semba, et al., Serum antioxidants, inflammation, and total mortality in older women, Am. J. Epidemiol. 163 (2006) 18-26. 